\title{
SALUD MENTAL GLOBAL: PERSPECTIVAS SOCIOCULTURALES Y ÉTICAS
}

Fernando Lolas Stepke ${ }^{1}$

Este número de Acta Bioethica recoge las ponencias presentadas en el simposio que sobre este tema se realizó en la ciudad de Santiago de Chile, los días 11 y 12 de enero de 2016. El tema fue el concepto de salud mental global, examinado desde distintas perspectivas por un conjunto de expertos de Canadá, Perú y Chile. Esta actividad fue parte de un proyecto conjunto entre el Centro Interdisciplinario de Estudios en Bioética de la Universidad de Chile y la Universidad McGill, de Montreal, Canadá. Para la producción de este número especial se contó, además, con el apoyo de CONICYT, Chile, Proyecto FP150009.

Además, como es habitual, se incluyen textos misceláneos previamente aceptados en el proceso de revisión por pares.

Las nociones de salud pública, epidemiología, salud internacional y salud global tienen relación con el tema de este encuentro. Cada una aporta matices distintos y complementarios. En el caso de la salud mental, es conveniente discernir entre la psiquiatría como especialidad médica, cada vez más "neurocientifizada" a tenor de la moda biologicista, y la salud mental como un elemento constitutivo de la vida de las personas. Como recalca Perales, salud mental no es reducible a psiquiatría y siempre involucra una consideración amplia y global de todo el entramado social. El artículo de Young, por su parte, destaca los factores de percepción social y, mediante un ejemplo concreto, ilustra las particularidades de las problemáticas involucradas.

En su importante trabajo, Alarcón destaca la necesidad de una postura "clínico-cultural" para abordar los desafíos de la salud individual y colectiva. La importancia de este enfoque queda subrayada por las aportaciones de Vicente y colaboradores y de Florenzano y coautores, quienes destacan el incremento de los problemas relacionados con el consumo de substancias, la morbilidad psíquica, los impactos de las catástrofes y la violencia, entre otros aspectos. La ponencia de Irarrázaval y colaboradores enfatiza la importancia de los factores evolutivos en la prevención de la morbilidad psicológica.

Temas como estos no pueden ser desligados del contexto creencial y valórico en que se presentan como problemas. De allí la alianza estratégica con el discurso bioético y la necesidad de considerar siempre la competencia cultural y las diferencias entre individuos y poblaciones para entender, proponer y resolver.

El exitoso simposio tuvo además una réplica, con los mismos ponentes, en el Instituto de Estudios Internacionales de la Universidad de Chile, como parte del programa de Ética Global que se ha instalado en dicho centro universitario.

Aparte de los textos escritos que recoge esta edición de Acta Bioethica, todas las conferencias fueron videograbadas y se encuentran disponibles en YouTube (uchile.tv). Como se trata de un diálogo permanente sobre temas que nunca se agotan, quedan los lectores de Acta Bioethica invitados a revisar dicho material y contribuir al permanente debate.

\section{In Memoriam: Duncan Pedersen}

Tras el simposio, la comunidad científica debió lamentar el prematuro deceso de uno de sus gestores, el doctor Duncan Pedersen. En su calidad de jefe del proyecto en el Douglas Institute de Montreal, fue él

${ }^{1}$ Director, Acta Bioethica. Profesor Titular, Universidad de Chile. Académico de Número, Academia Chilena de la Lengua, y Correspondiente, Real Academia Española; Académico Honorario, Academia Chilena de Medicina

Correspondencia: flolas@u.uchile.cl 
Salud Mental Global: perspectivas socioculturales y éticas - Fernando Lolas Stepke

quien concibió la idea de una serie de encuentros como el de Santiago, que culminarían en el habitual seminario de verano que realiza la Universidad McGill sobre salud mental inter y transcultural.

La sesión de este año en Montreal, a la que tuve posibilidad de asistir, se vio enriquecida por un recuerdo afectuoso de Duncan y sus muchas aportaciones a la salud mental global, la creación de un premio que lleva su nombre y la presentación formal del programa de salud mental global dirigido por el profesor Laurence Kirmayer.

Sea ésta ocasión propicia para dedicar a su memoria éste y otros trabajos, para destacar su figura y su obra como modelos para las nuevas generaciones y para continuar los infinitos detalles que sus estudios dejaron inconclusos. Todos y cada uno fueron fuente de inspiración y se ramificaron en direcciones amplísimas. 